\title{
Prevalence of Lip Competency among Nepalese Adolescents with different $\in$ thnic group of Kathmandu Valley
}

\author{
Dr Rajiv Yadav,' Dr Neelam Yadav, ${ }^{2}$ Dr Prem Basel${ }^{3}$ \\ 'Assistant Professor, Department of Dentistry, IOM, TUTH, ${ }^{2}$ Consultant Prosthodontist \\ ${ }^{3}$ Assistant Professor, Department of Com. Medicine and Public Health, IOM, TUTH
}

Correspondence: Dr Rajiv Yadav; Email: drrajivresearch@gmail.com

\section{ABSTRACT}

Introduction: Esthetic is one of the outcome that is expected from orthodontic treatment. In orthodontic practice, lip protrusion has been observed with proclined upper and lower incisors in bimaxillary protrusion. Such lip protrusion has been shown to be reduced with backward movement of the anterior teeth, which often accompanies premolar extraction. Hence the aim of our study is to find out prevalence of lip competency among Nepalese Adolescents with different ethnic group of Kathmandu valley.

Materials \& Method: It is a cross-sectional descriptive study. The study population included 14-18 year-old adolescents studying in high school of all three districts of Kathmandu Valley. An evaluation form was developed categorizing different levels of deep bite following WHO guidelines 1985 and accordingly data were recorded on it.

Statistical Analysis: Data were analyzed with descriptive statistics using the Statistical Package for the Social Sciences (SPSS for Windows, Version 23) in which p-values were calculated by Pearson Chi-Square Tests.

Result: Out of 935 screened students, $89.6 \%$ had competent lips and $10.4 \%$ had Incompetent lips. Female showed $91.9 \%$ of competent lips and $8.1 \%$ of incompetent lips. Male showed $87.8 \%$ of competent lips and $12.2 \%$ of incompetent lips. Among different ethnic group for lip competency, Advasi/Tharu showed $0.2 \%$, Brahmin/chettri showed 61.6\%, Dalit showed 0.6, janajatiHi showed 35.8\%, Madhesi showed 0.7\%,Muslim showed $0.6 \%$ and others showed $0.3 \%$. Among Brahmin/chettri $56.4 \%$ showed competent lips, $5.22 \%$ showed incompetent lips. However among Janajati-Hi $30.7 \%$ showed competent lips, $5.12 \%$ showed incompetent lips.

Conclusion: The Prevalence of competent lips was $89.6 \%$ and incompetent lips was $10.4 \%$. Among Genders both female and male showed higher percent of competent lips than incompetent lips. However competent lips were more associated with females. Among ethnic groups, Brahmin/chhetri have $61.6 \%$ of lip competency whereas Janajati-Hi have 35.8\%. Rest of the ethnic group have less than $1 \%$ of lip competency. Among Brahmin/chettri $56.4 \%$ have competent lips, $5.22 \%$ have incompetent lips where as Janajati-Hi $30.7 \%$ have competent lips, 5.12\% have incompetent lips.

Keywords: Competent lips, Incompetent Lips, High school students, Prevalence.

\section{INTRODUCTION}

In orthodontic practice, lip protrusion has been observed with proclined upper and lower incisors in bimaxillary protrusion.' Such lip protrusion has been shown to be reduced with backward movement of the anterior teeth, ${ }^{2-4}$ which often accompanies premolar extraction. ${ }^{5}$ The evaluation of lip protrusion is therefore important for making an orthodontic diagnosis, including determining the need for tooth extraction.

Esthetic is one of the outcome that is expected from orthodontic treatment. The meaning of esthetic in this view is not only the tooth alignment but also facial profile. Facial profile in orthodontic treatment mainly refers to lip protrusion or protrusion of perioral area. This problem is one of the reasons that induces orthodontic treatment especially found in female. ${ }^{6}$ Bimaxillary protrusion is the malocclusion that upper and lower incisors are proclined and soft tissue at perioral area is usually prominence. ${ }^{7.8}$ The prevalence of this type of malocclusion is commonly found in Asians, African- Americans 9.10 and commonly seen in Thais. ${ }^{9}$ The retraction of incisors can produce changes in facial profile and lip protuberance. Lip changes and amount of incisors retraction in this malocclusion were continuously presented in dental literatures. ${ }^{9,10-15}$ Competent lips are obligatory to have balance between the buccal and tongue muscles. A subject is classified as having competent lips when his lips are in light contact at clinical rest. ${ }^{16-20}$ Lip competence implies a tonus in the lip muscles to provide passive lip 
contact with no clinical contraction of the mentalis muscle. A subject is classified as having incompetent lips when his lips are apart at clinical rest or when his lips are in contact but present higher activity of the mentalis muscle, clinically verified by shrinkage of the chin skin. ${ }^{22}$ Further, subjects with short lips are not able to habitually close the lips without effort. ${ }^{20,22}$

Despite of fact that lip competency is directly associate with important criteria of treatment planning such as extraction of premolars, number of attached muscles, periodontal health, inclination of incisors and facial aesthetics limited studies can be cited in literature of Nepali. Hence this study was proposed. The general objective was to find out prevalence of lip competency among Nepalese Adolescents with different ethnic group.

\section{MATERIALS AND METHOD}

It is a cross-sectional descriptive study. The study population included 14-18 year-old adolescents studying in high school of all three districts of Kathmandu Valley. Multistage sampling process was adapted for study Sample and final sample size of 938 was derived out of 1097 screened that mate the inclusive criteria. Exclusion criteria: Subjects with craniofacial anomalies (clefts and syndromes) and non-Nepali nationals were excluded from the study). Clinical examination: students were examined at the schools, in a quiet classroom without external interference, under natural or artificial illumination. The examination lasted approximately 15 minutes per child, following the World Health Organization (1985) guidelines.10 The assessment of dental occlusion was carried out using latex gloves, dental mouth mirrors, and mill metric rulers. Students were examined by using dental probe and plane mouth mirror. Sufficient numbers of autoclaved instruments were made available to avoid the interruption during the study. After each day of examination, the entire instruments were autoclaved. Quality assurance: Training and calibration of examiner: Oral examination was performed by two trained and calibrated examiners. Before the survey, 60 students were examined by each of the two investigators to assess inter-examiner reliability and, Kappa values for both the examiners were found to be 0.87 and 0.88 respectively. Ethical consideration: An ethical clearance was obtained from the Ethical Review Board of Institute of Medicine. Each study individual was informed about the objective and benefit of the study. The informed consent form was developed to ensure consent of each study individual.

\section{STATISTICAL ANALYSIS}

Firstly, data were coded and entered into Excel sheet. To maintain the data quality (validity) rechecking and cross checking were done during data entry phase. After the entry of the data to excel sheet necessary data cleaning were done. Secondly, Data were analysed with descriptive statistics using the Statistical Package for the Social Scences (SPSS for Windows, Version 23) in which p-values were calculated by Pearson ChiSquare Tests. P-Value less than 0.05 were considered significant. 95\% Confidence Interval for proportion were also calculated.

\section{RESULT}

Out of 938 selected students $89.6 \%$ had competent lips and $10.4 \%$ had Incompetent lips at $95 \%$ of $\mathrm{Cl}$ (Table: 1 \& Figure 1). Female showed $91.9 \%$ of competent lips and $8.1 \%$ of incompetent lips. Male showed $87.8 \%$ of competent lips and $12.2 \%$ of incompetent lips (Table:2 \& Figure 2).

Among different ethnic group for lip competency, Advasi/Tharu showed $0.2 \%$, Brahmin/chettri showed $61.6 \%$, Dalit showed 0.6, janajati-Hi showed $35.8 \%$, Madhesi showed $0.7 \%$,Muslim showed $0.6 \%$ and others showed 0.3\% (Table:3, Fig 3). Among Brahmin/ chettri $56.4 \%$ showed competent lips, $5.22 \%$ showed incompetent lips. However among Janajati-Hi $30.7 \%$ showed competent lips, $5.12 \%$ showed incompetent lips. (Fig:4)

Table 1 : Lip Competency

\begin{tabular}{|c|c|c|}
\hline Competency type & Frequency & Percent with $95 \% \mathbf{C l}$ \\
\hline Competent & 840 & $89.6(0.87,0.91)$ \\
\hline Incompetent & 98 & $10.4(0.08,0.12)$ \\
\hline Total & 938 & 100.0 \\
\hline
\end{tabular}




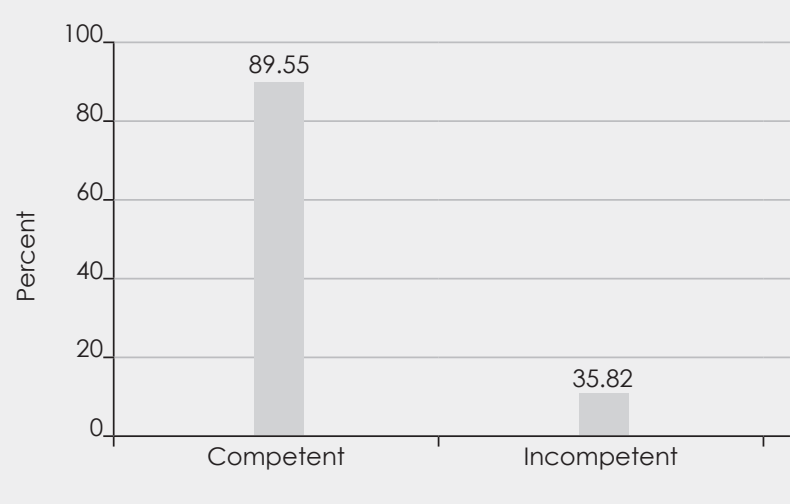

Figure 1: Lip competency

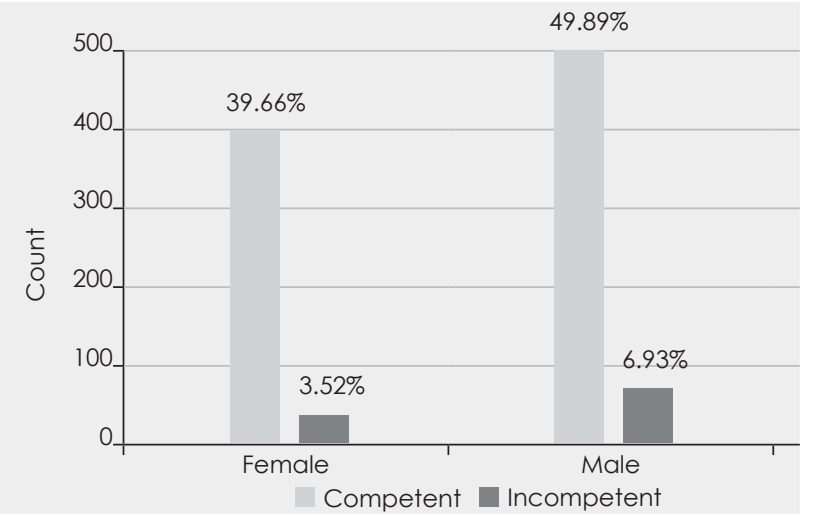

Figure 2: Gender-wise Lip competency

Ethnicity

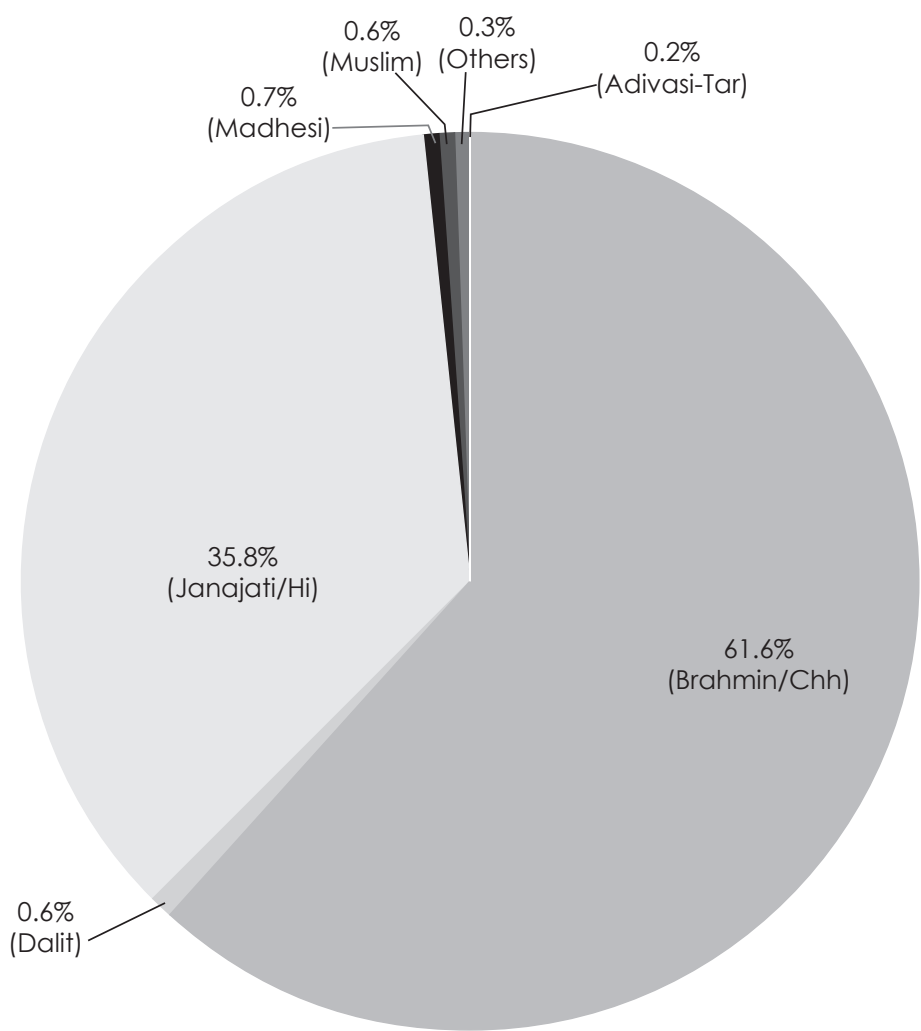

Figure 3: Ethnicity wise Lip Competency

Table 2 : Gender wise Cross tabulation of Lip competency

\begin{tabular}{|c|c|c|c|c|c|c|}
\hline \multirow{2}{*}{\multicolumn{3}{|c|}{ Competency type }} & \multicolumn{2}{|c|}{ Lip competency } & \multirow{3}{*}{\begin{tabular}{|c|} 
Total \\
405
\end{tabular}} & \multirow{2}{*}{ P Value } \\
\hline & & & Competent & Incompetent & & \\
\hline \multirow{4}{*}{ Sex } & \multirow{2}{*}{ Female } & Count & 372 & 33 & & \multirow{6}{*}{0.052} \\
\hline & & $\%$ within Sex & $91.9 \%$ & $8.1 \%$ & $100.0 \%$ & \\
\hline & \multirow{2}{*}{ Male } & Count & 468 & 65 & 533 & \\
\hline & & \% within Sex & $87.8 \%$ & $12.2 \%$ & $100.0 \%$ & \\
\hline \multirow{2}{*}{\multicolumn{2}{|c|}{ Total }} & Count & 840 & 98 & 938 & \\
\hline & & \% within Sex & $89.6 \%$ & $10.4 \%$ & $100.0 \%$ & \\
\hline
\end{tabular}


Table 3: Ethnicity * Lip competency Cross tabulation

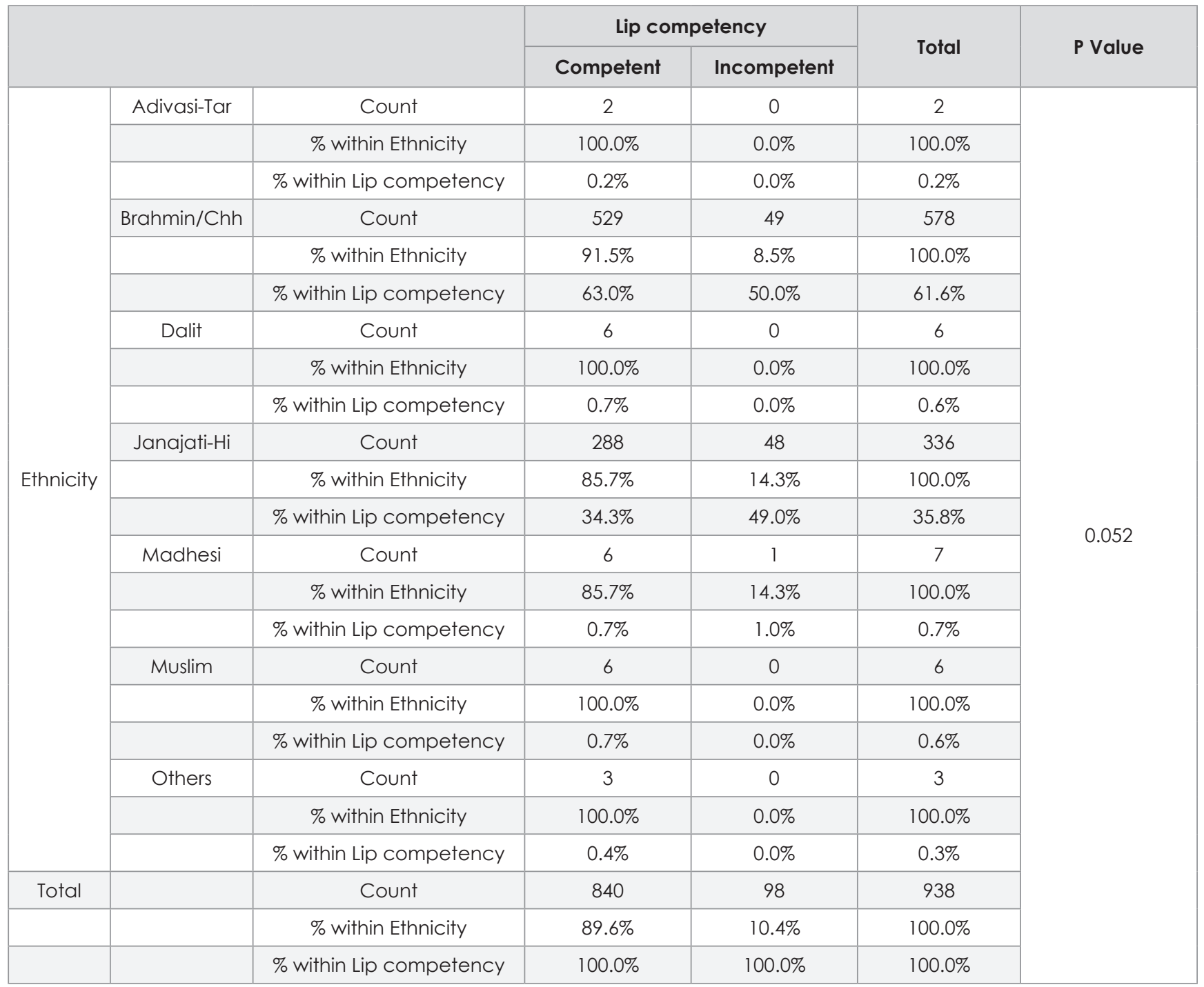

\section{DISCUSSION}

Kikelomo Adebanke Kolawole et al, 2010 did study on Nigerian population which shows majority of the children had competent lips (97.1\%). Only 7 of all the children had incompetent lips 4 of whom were boys. ${ }^{23}$ Another study on Nigerian population by Philip $U$ Ogordi et al, 2019 showed $85.7 \%$ competent lip \& $14.3 \%$ incompetent lips. ${ }^{24}$

Laila Al Jadidi et al, 2018 states that Omani population showed $94.8 \%$ lip competency \& $5.2 \%$ showed lip incompetency. ${ }^{25}$

Marziya et al (2015) in Pakistani population showed competency of lip was found in $67.4 \%$ of patients and absent in $31.8 \%$ of patients. ${ }^{26}$

Our study on Nepalese population also showed relatively similar findings. Our population also represents higher percentage of competent lips where as only
1/10 of total sample showed Incompetent lips. Female showed more of competent lips where as incompetent lips were more associated with male participants.

\section{CONCLUSION}

The Prevalence of competent lips was $89.6 \%$ and incompetent lips was $10.4 \%$ (Percent with $95 \% \mathrm{Cl}$ ). Among Genders both female and male showed higher percent of competent lips than incompetent lips. However competent lips were more associated with females. Among ethnic groups, Brahmin/chhetri have $61.6 \%$ of lip competency whereas Janajati-Hi have $35.8 \%$. Rest of the ethnic group have less than $1 \%$ of lip competency. Among Brahmin/chettri $56.4 \%$ have competent lips, $5.22 \%$ have incompetent lips where as Janajati-Hi $30.7 \%$ have competent lips, 5.12\% have incompetent lips. 


\section{REFERENCES}

1. Leonardi R, Annunziata A, Licciardello V, Barbato E. Soft tissue changes following the extraction of premolars in nongrowing patients with bimaxillary protrusion. A systematic review. Angle Orthod 2010;80:21 1-6.

2. Tan TJ. Profile changes following orthodontic correction of bimaxillary protrusion with a preadjusted edgewise appliance. Int $J$ Adult Orthodon Orthognath Surg 1996;11:239-_51.

3. Hayashida $\mathrm{H}$, loi H, Nakata S, Takahashi I, Counts AL. Effects of retraction of anterior teeth and initial soft tissue variables on lip changes in Japanese adults. Eur J Orthod 2011:33:419-26.

4. Bourzgui F, Alami S, Sebbar M, Derkaovi T, Hamza M, Serhier Z, et al. Effect of orthodontic treatment on lip position. Int Orthod 2013; 1 :303-13.

5. Kusnoto J, Kusnoto $\mathrm{H}$. The effect of anterior tooth retraction on lip position of orthodontically treated adult Indonesians. Am J Orthod Dentofacial Orthop 2001;120:304-7.

6. Suntornlohanakul S, Tianviwat S, Songwattana P. The adolescent's experience in receiving orthodontic treatment with fixed appliances: a case study at Faculty of Dentistry, Prince of Songkla University. J Dent Assoc Thai 2004; 54(6):329-37.

7. Diels RM, Kalra V, DeLoach Jr N, Powers M, Nelson SS. Changes in soft tissue profile of African-Americans following extraction treatment. Angle Orthod 1995;65(4):285-92.

8. Lewis SJ. Bimaxillary protrusion. Angle Orthod 1943;13(3):51-9.

9. Lamberton CM, Reichart PA, Triratananimit P. Bimaxillary protrusion as a pathologic problem in the Thai. Am J Orthod. 1980 Mar;77(3):320-9.

10. Rains MD, Nanda R. Soft-tissue changes associated with maxillary incisor retraction. Am J Orthod 1982; 81 (6):481-8.

11. Lew K. Profile changes following orthodontic treatment of bimaxillary protrusion in adults with the Begg appliance. Eur $\mathrm{J}$ Orthod 1989;11(4):375-81.

12. Talass MF, Talass L, Baker RC. Soft-tissue profile changes resulting from retraction of maxillary incisors. Am J Orthod Dentofacial Orthop 1987:91(5):385-94.

13. Yogosawa F. Predicting soft tissue profile changes concurrent with orthodontic treatment. Angle Orthod 1990;60(3): 199-206.

14. Yasutomi H, loi H, Nakata S, Nakashima A, Counts AL. Effects of retraction of anterior teeth on horizontal and vertical lip positions in Japanese adults with the bimaxillary dentoalveolar protusion. Orthod Waves 2006;65(4):141-7.

15. Kusnoto J, Kusnoto $\mathrm{H}$. The effect of anterior tooth retraction on lip position of orthodontically treated adult Indonesians. Am $\mathrm{J}$ Orthod Dentofacial Orthop 2001;120(3):304-7

16. Gustafsson M, Ahlgren J. Mentalis and orbicularis oris activity in children with incompetent lips: an electromyographic and cephalometric study. Acta Odontol Scand. 1975;33:355-363.

17. Simpson MM. An electromyographic investigation of the perioral musculature in Class II division 1 malocclusion. Br J Orthod. 1977;4:17-22.

18. Yemm R, El-Sharkawy M, Stephens CD. Mesurement of lip posture and interaction between lip posture and resting face height. J Oral Rehabil. 1978;5:391-402.

19. Harradine NWT, Kirschen HES. Lip and mentalis activity and its influence on incisor position - A quantitative electromyographic study. Br J Orthod. 1983;10:114-127.

20. [9] Yamaguchi K, Morimoto Y, Nanda RS, et al. Morphological differences in individuals with lip competence and incompetence based on electromyographic diagnosis. J Oral Rehabil. 2000;27:893-901.

21. Tomiyama N, Ichida T, Yamaguchi K. Electromyographic activity of lower lip muscles when chewing with the lips in contact and apart. Angle Orthod. 2004;74:31-36.

22. Tosello DO, Vitti M, Berzin F. EMG activity of the orbicularis oris and mentalis muscles in children with malocclusion, incompetent lips and atypical swallowing part I. J Oral Rehabil. 1998;25:838-846.

23. Kolawole KA, Otuyemi OD, Oziegbe EO. The relationship between malocclusion, lip competence and gingival health in a group of school children. Rev Clín Pesq Odontol. 2010 set/dez;6(3):239-47

24. Ogordi PU, Ize-lyamu I N, Adeniyi E O. Prevalence of traumatic dental injury to the anterior teeth in children attending paramilitary and nonparamilitary schools in Nigeria. Ann Afr Med 2019;18:80-5

25. Al Jadidi L, Sabrish S, Shivamurthy PG, Senguttuvan V. The prevalence of malocclusion and orthodontic treatment need in Omani adolescent population. J Orthodont Sci [serial online] 2018;7:21

26. Marziya, Inam J,Virda M, Munur B et al. Incidence of trauma to anteriors and its associated etiological risk factors Pakistan postgraduate medical journal Vol. 26 No. 1 Jan. - Mar. 2015 